\title{
Selling Health Promotion to Corporate America: Uses and Abuses of the Economic Argument
}

\author{
Kenneth E. Warner, PhD
}

Economic considerations constitute a significant factor in businesses' interest in adopting health promotion (HP) programs and in the wellness community's attempts to sell such programming to business. Substantial elements of both the business and wellness communities believe that HP programs are financially profitable, in addition to, and as a result of, improving employees' health. Examination of the foundation of this belief, however, leads to the conclusion that underlying analyses have been technically flawed and have ignored important costs of HP programs. This article discusses the limitations of these analyses and outlines the framework of a model that could provide a sound assessment of the economics of workplace HP programs. In general, it is expected that resultant analyses would find less direct profit potential in workplace HP programs but would emphasize the cost-effectiveness of many such efforts. The latter would force recognition that health, and not profit, is the principal benefit of health promotion programming. The distinction between the cost-effectiveness and cost-saving potential of health promotion is one that all interested parties should master.

\section{INTRODUCTION}

Corporate America is eying health promotion (HP) with the prospect of a long-term relationship in mind. While the current relationship hardly qualifies as a full-blown romance-casual dating might be a more apt characterization-recent evidence demonstrates that limited health promotion programming is fairly common within the corporate sector, particularly among larger firms. ${ }^{1}$ Furthermore, increasing numbers of major companies are adopting relatively complete models of wellness programming.*

As with all courting, the future of the relationship between business and health promotion is quite unpredictable. However, as with all budding romances, a mutual sense of optimism dominates expectations. The romance is not one-sided. The business community finds the health promotion community aggressively seeking corporate suitors and quite prepared to arrange marriages. Many elements of the business community are quite receptive. Interest in the business community derives from several economic motivations, as well as a less profit-driven concern for the welfare of employees. Interest in the wellness community reflects recognition that, in the 1980s, the

*For the purposes of this article, the terms "health promotion" and "wellness" will be treated as synonymous. For recent discussions of definitional distinctions between these and other terms, see Leviton et al. ${ }^{2}$ and Terborg. ${ }^{3}$

Kenneth E. Warner is Professor and Chair, Department of Public Health Policy and Administration, School of Public Health, University of Michigan, Ann Arbor, MI 48109-2029. 
workplace is the most promising locus for the development and diffusion of substantial health promotion activity.

When the terms of a firm's marriage to wellness programming are being discussed, the business expresses interest in receiving economic gifts as a substantial part of the dowry. The health promotion matchmaker rarely hestitates to offer such gifts. If economic benefits comprise a major section of the marriage contract, it behooves both bride and groom to be open and honest and well-informed about the economic aspects of the intended relationship. Today, however, each party possesses only the most rudimentary knowledge of the economics of HP programming, and both corporate buyers and wellness community sellers are all too eager to accept the best possible interpretation of the economic gifts that health promotion has to offer. If this interpretation is not realized-and a growing body of evidence suggests that it may not be-one wonders about the long-run stability of the relationship.

The purpose of this article is to examine the economic argument in workplace health promotion programming: its nature, significance, and validity. Toward that end, the next section of the article discusses the principal factors that motivate interest in workplace health promotion within the business and wellness communities. The succeeding two sections dissect the economic argument to ascertain how workplace HP programming produces economic benefits and costs. The first of these sections critically examines the conventional wisdom on the economics of health promotion. Drawing on this critique, the second of the two sections discusses how one should model an ideal economic evaluation of a health promotion program, speculates on what one might learn, and considers the appropriate interpretation and use of findings.

At the outset, it must be emphasized that this analysis is conceptual, not empirical, and somewhat speculative at that. While many analysts have considered the economic dimensions of health promotion programs, few have structured their analyses in a manner that would effectively and comprehensively capture all of the relevant economic issues. Thus, while the body of existing literature is informative, it is far from definitive.

\section{FACTORS MOTIVATING WORKPLACE HEALTH PROMOTION}

No one knows precisely how much health promotion programming is occurring in the business community. An empirical assessment of the matter requires a sophisticated and elaborate survey, and given the apparent rapidity of change in the adoption of such programming, ${ }^{1,4}$ survey results are likely to be dated by the time a survey can be completed and results released. Furthermore, conceptual issues muddy the waters: there is no widely accepted definition of what constitutes health promotion programming. ${ }^{4}$ It is clear that if one includes trational occupational safety and health activities, such as production line accident prevention, "health promotion" will appear much more commonplace than if one restricts attention to health-related behavior modification (e.g., diet, smoking, exercise). ${ }^{1}$ Nevertheless, activity in the latter category is definitely increasing and the survey evidence paints a picture of rapid growth in overall HP programming from the late 1970s into the early $1980 \mathrm{~s}^{1,3,4}$ (and personal 
communication, Jonathan Fielding, December 20, 1985).* Given the intense interest in HP programming exhibited since then in both the professional and trade literature, it seems reasonable to assume that the level of new activity has not subsided.

\section{Reasons for Companies' Interest in Health Promotion}

The reasons for the business community's interest in health promotion range from the personal health experiences of company executives (e.g., the company president's starting a fitness program after surviving a heart attack) to carefully calculated financial assessments that find economic merit in health promotion. Both of these kinds of motivation seem to play significant roles in the adoption and dissemination of workplace health promotion, as do several others. Within the professional and trade literature, however, interest concentrates on the economic merits of health promotion programs: do they reduce health care costs? Do they decrease life insurance premiums? Do they increase productivity? Do they reduce absenteeism, turnover, disability, etc.?

The treatment of the economic issues within the trade and professional literature is not uniformly analytical. In general, the trade publications have adopted a much more anecdotal approach: they tend to describe individual programs and draw economic conclusions from often simplistic evaluations; a distinct flavor of unfettered enthusiasm and advocacy is apparent. The professional journals, by contrast, publish many more genuinely analytical assessments of the economic implications of health promotion programs, although, as is discussed later in this article, these analyses typically are not sophisticated, nor are they entirely devoid of enthusiasm and advocacy.

\section{Economic Considerations}

The economic concerns of the business community can be categorized as direct and indirect; within each of these, some of the costs and benefits will be readily measurable while others will not. The most immediate and familiar costs are direct and measurable. These consist primarily of expenditures for program inputs (labor, supplies, facilities) and employees' time off from work to participate in the programs. Less immediate and generally unfamiliar costs are indirect consequences that are measurable in concept but occur so far in the future as to commonly go wholly unrecognized. The principal costs in this category, discussed in the next section of the article, are the pension costs and later health care and disability costs experienced by employees who remain on the job, or alive during retirement, thanks to the success of a health promotion program.

\footnotetext{
*In part, the rapid rate of growth documented in recent surveys 1,4 may be an artifact reflecting the changing ages over the relevant years of the companies surveyed. If a larger proportion of the companies were newly established in the earlier years, they might be expected to initiate fewer health promotion activities at that time, compared with the more recent years in which they might be larger, more profitable, and more stable. This fuctor seems unlikely, however, to explain more than a fraction of the growth described in the studies.
} 
The direct economic benefits include reductions in a variety of "insurance" costs, including health care, life insurance, disability (short- and long-term), and workers' compensation, and improvements in labor productivity, such as reductions in absenteeism and turnover and increases in the productivity of workers while on the job. Indirect benefits include improvements in employee job satisfaction and the ability to recruit healthy, highly motivated employees, and a general polishing of "corporate image."*

While each of these economic factors receives attention in the business community, clearly the driving force in business' economic interest in HP is health care costs, their level, and their rate of growth. Employers pay about $80 \%$ of all private health insurance premiums, ${ }^{5}$ thereby assuming responsibility for between one-fifth and onefourth of the nation's entire bill for personal health care services, estimated at more than $\$ 400$ billion in $1985 .^{6}$ Depending on the nature and depth of coverage, area of the country, and other factors, employers annually pay out up to several thousand dollars per employee in health care expenditures. At Ford Motor Company, as one high-cost example, the annual cost of health care for employees, their dependents, and retirees approaches $\$ 5000$ per active employee (personal communication, December 19, 1985).

While the cost of health care is a source of substantial current concern, the rate of growth in health care costs is the added dimension that has activated the business community to seek means of containing their health care costs. In the two decades since 1965, while the Gross National Product rose by a factor of 5.8, national health expenditures increased tenfold. Most recently, in the first four years of the current decade, GNP rose by just over one-third $(36.7 \%)$ and health expenditures grew by almost two-thirds $(65.3 \%){ }^{6}$ As the nation's principal buyer of private health insurance, business in general has shared this national experience, and indeed contributed to its evolution. However, many businesses have experienced much more rapid growth in their health care liabilities, reflecting such factors as the expansion of employee health benefits and the aging of work forces.

The business community has adopted, and is exploring, a wide variety of approaches to containing health care costs and their growth. Prominent among these are utilization of Health Maintenance Organizations and Preferred Provider Organizations, insurance incentives including deductibles and copayments, utilization review programs, ambulatory surgery, and second-opinion surgery programs. For each of these, cost containment is the sole significant objective; improvement in employees' health is either incidental or even contrary to expectation. Health promotion, by contrast, is expected to achieve cost containment benefits through improvements in employees' health. Indeed, it can be argued that it is precisely this duality-the cost containment potential and prospective health benefit-that makes health promotion a candidate for consideration as a cost containment measure. For a number of reasons that will emerge latter in this article, it seems unlikely that health promotion would be considered a viable competitor to alternative delivery systems and insurance incen-

\footnotetext{
*While the distinction between direct and indirect benefits may be conceptually straightforward, disentangling them at an empirical level may be virtually impossible. For example, a health promotion program can reduce absenteeism for two conceptually distinct reasons: by improving employees' fitness, it reduces days of physical illness or disability; by improving job satisfaction, it reduces "sick days" taken off simply to use up sick leave. These effects would be difficult to distinguish empirically.
} 
tives if it had to compete solely on the basis of health care cost containment potential.

\section{Other Considerations}

Several important motivators of business health promotion should not be characterized as being primarily economic in nature, although an underlying concern with economic implications may play a role in each. In their survey of Colorado businesses, Davis et al. found that, among the companies having existing health promotion programs, improvement of employee health was by far the leading reason for initiating the program, identified by $82 \%$ of the firms. The second most common reason was to improve employee morale (59\%), and three additional common responses also have a noneconomic flavor: response to employee demand or interest $(33 \%)$, to be part of an innovative trend (32\%), and to improve the business' public image (20\%). Three clearly economic considerations also rated highly: reduction of health care costs $(57 \%)$, reduction of turnover and absenteeism $(51 \%)$, and improvement in productivity $(50 \%)^{4}$

When Davis et al. queried companies not having health promotion programs but expressing interest in starting them, the relative weights of the motivating reasons shifted considerably. Improvement in employees' health remained the number one attraction (68\%), but only by an insignificant margin over the principal economic concern: reducing health care costs $(67 \%)$. The next two factors were also economic: improving productivity (64\%) and reducing turnover and absenteeism (57\%). The second leading reason among the firms which had programs-improving employee morale-fell to fifth place among firms contemplating programs $(52 \%)$. The other noneconomic reasons were acknowledged by only one-tenth to one-fifth of the respondents. $^{4}$

Among the potential explanations of the differences between firms with and without programs is the possibility that the firms that had already made a commitment to employee health promotion programs were simply more selflessly interested in the welfare of their employees. Conceivably, they were larger and/or more profitable, and hence under less pressure to be concerned with the bottom-line implications of health promotion. It is also plausible that their experience with health promotion programs had led them to appreciate the employee benefits more than the economic ones; perhaps the former were more self-evident. In any case (and many other explanations can be offered), if the difference is more than an anomaly in the group of businesses studied, the finding suggests that economic considerations may play an increasingly important role in the future growth of workplace health promotion. The unavailability of a more refined breakdown in the published study, however, makes this conclusion highly conjectural.

The cynic might argue that all of a firm's actions ultimately derive from a concern with "the bottom line" and that the ostensibly altruistic motivations noted earlier are actually economic at their core. A more charitable, and likely realistic, reading is that underlying motivations vary substantially from firm to firm and from one executive to another within a firm. There is little doubt that a genuine interest in the welfare of employees has motivated some of the firms that have thus far adopted health promotion programs. 
An additional factor related to employee welfare is responsiveness to the health promotion objectives of organized labor, a more specific instance of what Davis et al. categorized as "response to employee demand or interest." 4 Health promotion programming can be an item included in labor contract negotiations. While it does not compete in importance with the bread-and-butter issues, nor with basic benefits, several recent major contracts have included provisions pertaining to health promotion. The future of labor demand for health promotion rests in large part on convincing labor of the desirability of HP programming. This may be most difficult for the employee groups that might derive the most benefit from health promotion, e.g., blue-collar assembly line workers.

Certainly an important factor in the growth of workplace health promotion has simply been the "fad." This is reflected in the finding of Davis et al. that one-third of respondent companies that had adopted health promotion programs identified the desire "to be part of an innovative trend," and that $11 \%$ of companies expressing interest shared this motivation. ${ }^{4}$ The fad of health promotion has spread into many sectors of our society, as is seen in the evolution of health promotion agencies in the federal and state governments, in the televised pitch for "healthy" breakfast cereals, in the booming sales of jogging shoes, and in the everyday behavior of consumers. Thus, in part the popularity of health promotion in business is simply a reflection of a broader societal acceptance of the HP message. ${ }^{3}$ Ultimately, the future of health promotion in the workplace likely rests as much on this general proclivity toward fitness as on its inherent health and economic benefits.*

\section{Reasons for the Wellness Community's Interest in the Workplace}

The workplace has many inherent attractions to health professionals interested in promoting the wellness movement. In addition, in an era of less government and more reliance on private sector voluntarism, the prospect of enlisting business support for health promotion becomes increasingly attractive, or essential.

The two most fundamental attractions of the workplace are the length of time that people spend there and the fact that, while there, they constitute a "captive audience," in both physical and psychological dimensions. The time factor is self-evident: during the work week, the typical worker is on the job one-third or more of the day; close to $50 \%$ of the waking hours are spent working. The "captive audience" feature refers both to the fact that people are regularly physically present, with the use of their time often prescribed by some superior, and they are subject to powerful influences encouraging conformity. The latter can include peer pressure, reflecting the natural community that often exists within the work setting, the shared norms and values, and also employerprovided incentives, including financial inducements to participate in a health promotion program and nonfinancial encouragement such as use of company time or facili-

*Ironically, workplace health promotion programs are likely to find greatest acceptance among the types of workers likely to benefit least from them, namely white-collar workers. These workers are already more receptive to the health promotion message than are blue-collar workers, as seen in their relatively lower rates of smoking, higher prevalence of regular exercise, and so on. With the fad of health promotion not having caught on as much among the blue-collar population, this would seem to be the group that might benefit most from workplace HP programs. Yet this is also the group most likely to perceive HP programs as competing with bread-and-butter benefits. 
ties. ${ }^{7,8}$ That these influences encourage participation and compliance is indicated by surveys that find consistently higher levels of both participation and compliance in workplace HP programs than in similar programs offered in the community. ${ }^{9}$

A third attraction of the workplace is that the labor force consists of groups believed to be either highly receptive to health promotion efforts (i.e., white collar) or very much in need of them in terms of the prevalence of unhealthy behaviors (i.e., blue collar). With either motivation or need high, the potential to have a substantial impact is believed to be great. The attractiveness of the workplace in this regard could decrease over time if wellness could be inculcated in another captive audience-school children-since increasingly smaller proportions of the work force would then reach the working years burdened with the kinds of habits that HP programs address.

Other features of the workplace add to its potential as a locus of health promotion. The daily gathering of workers, already noted, facilitates communication about, delivery of, and compliance with programs, as does the existence of internal communications systems effectively in place (e.g., company newsletters and informal word-of-mouth networks). The workplace adds convenience to the factors already mentioned: commuting time, travel costs, and the psychological barrier of having to get from one place to another are all avoided. Finally, medical personnel are often already present, so that a health promotion program can be integrated into an established company concern with employee health. This lends credibility to the effort, in addition to taking advantage of existing resources. ${ }^{10}$

A final attraction of the workplace is the ready opportunity to introduce a variety of incentive programs to foster participation and compliance. To date, the notion of motivating health promotion participation or compliance through the use of specific incentives has received limited attention. Examples of incentives that have been offered in the business community include paying employees a weekly bonus if they do not smoke on the job; offering prizes to the competing group within a firm that manages to lose the most collective weight; and holding a lottery for an all-expensepaid vacation for employees who sign a pledge to wear their seatbelts, assuming that the employee group as a whole attains a pre-specified level of belt use. Given the large number of diverse kinds of businesses, and of employee populations, there is an opportunity to introduce a large and varied set of HP incentives. Evidence accumulated to date suggests that incentives can play an effective role in motivating behavioral change. ${ }^{7,8}$

\section{THE ECONOMIC ARGUMENT: THE CONVENTIONAL WISDOM}

As noted at the outset of this article, a significant selling point, and buying consideration, for workplace health promotion programs is the notion that they represent sound financial investments, in addition to (and as a result of) enhancing the health of employees. The argument is a simple one: avoidable, behavior-related illnesses impose costs on businesses in the form of higher health insurance premiums, life insurance, disability, workers' compensation, sick pay, turnover, and absenteeism, and lower productivity. That these costs are substantial is beyond dispute. Two former officials of the Atlantic Richfield Company have estimated that they run some $\$ 55$ million per year for ARCO, a company with approximately 39,000 employees. ${ }^{11}$ Health promotion programs can be mounted relatively inexpensively and, by altering 
the deleterious behavior, can eliminate some or all of these costs. If the cost savings exceed the costs of running the programs, the programs will represent a sound financial investment.

The clear assumption of the vast majority of health promotion proponents is that savings can and will exceed program costs, and by a considerable margin. The trade literature exhibits a wholly uncritical enthusiasm for this perspective and much of the scholarly literature supports it as well, although the leading writers often temper their enthusiasm (which is nonetheless quite evident) by offering modest cautions. These cautions often relate to the major costs that evade attention in the vast majority of the analyses of workplace health promotion: later health care costs (and disability, etc.) and pensions for employees who live longer as the result of successful health promotion efforts. For example, in an analysis of the costs and benefits of workplace smoking cessation programs, in which he found a net financial benefit, Kristein noted that the pension implications of success in smoking cessation were not included in his costbenefit calculus. ${ }^{12}$ (In an article on the same subject published the preceding year, he did not even mention the pension issue. ${ }^{\mathbf{1 3}}$ ) In a prominent, early article on the economics of workplace health promotion, Fielding raised the matter of graduates of HP programs experiencing later health care costs as the result of not succombing to diseases at an earlier stage of life. He dismissed these deferred costs as being largely the responsibility of the federal government and not the business community, as many of the costs will occur after age 65 and eligibility for Medicare coverage. Fielding concluded that "current evidence suggests a very favorable return on investment for disease prevention and health promotion programs," although he called for more and better research and evaluation. ${ }^{14}$

Cautions such as those offered by Kristein and Fielding have represented the exception, rather than the rule. As these examples illustrate, even the more reasoned analyses historically have supported the conventional wisdom that health promotion programs are sound financial investments. A reading of the most recent scholarly literature, however, suggests that the conventional wisdom is coming under assault, the object of analytical missiles fired at evaluation terrain which is undefended and appears analytically indefensible. While the analysis underlying the conventional wisdom is in jeopardy, however, the implication for the conclusion of that wisdom is less clear. That is, the predominant form of analysis of workplace health promotion programs is fatally flawed, as is discussed immediately following; but the conclusion that health promotion programs can represent sound financial investments is not thereby destroyed. It will have to be modified and qualified and reevaluated.

\section{Flaws in the Conventional Wisdom: Ignoring Later Costs}

As noted earlier, to the extent that workplace health promotion programs succeed in prolonging life, two costs of such programs occur relatively far into the future. For this reason, and because they are indirect, they commonly go wholly unrecognized. These are the pension costs incurred when graduates of certain HP programs live longer into the retirement years, and the health care, disability, and other costs that similarly are incurred because graduates live to be older-both older workers and older retirees.

Perhaps the best example of the pension cost is the case of smoking cessation. With two-thirds of the victims of smoking-related diseases dying after age 65 , smoking takes 
its greatest mortality toll in the retirement years. Thus smoking cessation achieves its greatest mortality-avoidance benefit in those same retirement years. At present, in the crudest of economic terms, smoking-related mortality occurring after retirement represents a financial benefit to the firm, because it reduces the population of retirees drawing pensions. Thus, to the extent that they are successful, smoking cessation and other life-extending health promotion interventions will add a pension cost to the firm's labor-related financial obligations.

The issue of the relative economic importance of enlarged pension obligations and the commonly noted decreases in health care and related costs (and increases in productivity) has yet to be resolved, in large part because few analysts have studied it. Only a handful of writers have even acknowledged the existence of the pension issue. One group of analysts has concluded that, in the case of smoking cessation, the lifeextending potential of workplace health promotion is of sufficient magnitude that the resultant pension obligations outweigh all of the associated health care and related cost savings. ${ }^{15}$ This study is not definitive, but it vividly illustrates an inescapable and enormously important conclusion: if one is truly interested in assessing the economic implications of workplace health promotion from the perspective of the profit-maximizing employer, one cannot ignore pensions. For workplace HP programs that achieve significant life extension into the retirement years, adding pensions to the economic calculus means that net economic benefits necessarily will be lower than those calculated without considering pension implications. Pension policies can be altered-pensions can be reduced or the retirement age extended (both contrary to current trends) - but absent substantial structural change that the labor force will not appreciate, the very success of certain health promotion efforts will impose a substantial financial burden on employers.*

The logic of the implication of health promotion for employers' later health care costs, life insurance, disability, productivity, etc., is similar: if health promotion works to extend life, the work force will become older. Other things being equal, we would expect an older work force to have more chronic illness and disability, to be less agile, and so on, each of which would imply additional costs to the employer. A basic presumption of health promotion, however, is that healthier lifestyles will reduce illness and disability at all ages, i.e., that other things will not be equal. At the extreme, Fries posits the compression of morbidity, the idea that optimal lifestyle will produce optimal health until just prior to death at the natural limit of the lifespan. ${ }^{18}$ The point here is simply that workers who are "saved" by health promotion are unlikely to go through the rest of their work careers free of any illnesses or any dimunition in their work capacity. Thus any such later costs, made possible by the successes of health promotion, must be recorded as debits on the employer's health promotion financial balance sheet.

Later health care and pension costs of health promotion graduates will not affect

*This phenomenon applies to the public sector as well, particularly to the federal government. Life-extending health promotion programs will impose their largest relative burden on the federal government through their impact on Medicare and, especially, Social Security. ${ }^{16}$ The fact that smoking currently accounts for an estimated $\$ 4.2$ billion in federal government financed health care costs was used recently by representatives and senators to argue for an increase in the federal cigarette excise tax and an earmarking of some of the new revenues to help pay for Medicare. The irony is that the same government study that produced the $\$ 4.2$ billion estimate also cautioned that Medicare and Social Security obligations might increase in response to widespread reduction in the smoking population. ${ }^{17}$ 
employers equally. As Fielding noted in his discussion of "the bottom line,"14 the later health care costs of HP successes will occur to a large degree in the retirement years, years during which Medicare assumes much of the financial responsibility; such is not the case for pensions (Social Security constituting a small proportion of retirement income for employees covered by reasonable company pension plans). For many companies, however, especially larger ones with unionized work forces, supplemental health insurance for retirees is a common benefit, one that is not inconsequential economically and may increase in importance in the coming years if the federal government continues to reduce Medicare benefits. The possible importance of this is suggested by evidence that a nonsmoking population may consume approximately the same total health care resources as a population including smokers, although the former will have more people living longer lives and incurring medical costs later in life. ${ }^{19}$

\section{Other Flaws}

The analysis underlying the conventional wisdom about the economics of workplace health promotion can be faulted for a number of technical problems, analytical errors of omission and commission. These problems are found even in the very recent literature published in well-respected journals and magazines. Among the more prominent are the following:

1. Analysts often use the most optimistic estimates in projecting long-term success rates of health promotion programs, instead of average or common figures.

2. Compliance with a behavioral change regimen is sometimes treated as being synonymous with the elimination of the rist associated with the undesirable behavior, which it clearly is not. For example, while the mortality risk of people who quit smoking drops precipitously, former smokers retain a mortality risk in excess of that of the never-smoker throughout their lives, with the former smoker's risk of death closely approaching that of the never-smoker only 15 or more years after cessation. $^{20}$ Despite this obvious and important fact, many analysts have adopted the health experience of the never-at-risk population as the instant new health profile of the health promotion behavioral success. More conscientious analysts do take the lag in achieving full benefits into consideration. ${ }^{2,12}$

3. Many studies fail to even attempt to project program consequences into the more distant future. Often the basis for this decision is that it is too difficult to project distant outcomes with any sense of confidence as to their validity. While one must have some sympathy with this consideration, it is precisely those future years in which many of the more interesting program-related phenomena will occur (e.g., pensions and later health care costs). Thus, even the most analytically rigorous studies that adopt this restriction necessarily ignore potentially important economic implications of HP programming. ${ }^{2}$ Of course, if employers have the same time horizon, taking the short-term view of investment decisions (a matter we will consider later), the restriction will conform to employers' self-perceived needs, even while it will fail to provide a complete picture of the long-term implications of HP programming.

4. Among the more sophisticated analytical issues is the handling of consequences occurring beyond the first year of a program. The appropriate treatment of future benefits and costs is to discount them by a discount factor reflecting the 
company's opportunity cost of investment capital. ${ }^{21}$ While discounting is incorporated into the best studies, ${ }^{2}$ it is found very rarely in the workplace HP literature. Typically, authors look only at one-year implications, or they simply add up future years' costs or benefits as if the passage of time is irrelevant.

\section{TOWARD VALID ECONOMIC ANALYSIS}

The preceding discussion should suggest essential elements of a comprehensive, technically sound analysis of the economics of workplace health promotion programs. Those elements are summarized here. Attention then turns to the conclusions one might anticipate from this kind of assessment. The section closes with comments on the appropriate interpretation and use of the findings of such an analysis.

\section{Modeling the Economics of Workplace Health Promotion}

Health promotion programming is an excellent example of a function that addresses multiple business objectives, including better employee relations and stronger corporate image, as well as the economic well-being of the enterprise. A complete economic analysis must recognize all of these elements. For obvious reasons, the strength of the analysis will lie in those areas which are most identifiable, quantifiable, and meaningfully convertible into dollars and cents. Others must be accorded explicit, perhaps independent recognition, and some may be incorporated into the formal quantitative analysis through techniques such as sensitivity analysis. ${ }^{2 \mathrm{I}}$

A sound, comprehensive assessment of workplace HP economics would have to consider all of the economic parameters of interest, including health care costs, life insurance, short- and long-term disability, workers' compensation, sick pay, turnover, absenteeism, productivity, and pensions. The implications in later years, as well as in the near term, would have to be examined for all of these variables. Furthermore, attention would have to be accorded the intangibles, including such items as employee morale, company image, and the inherent value of better employee health (i.e., the value to employees themselves and to society, beyond the contributions to the economic concerns listed first). The technical dimensions of the analysis would call for realistic appraisals of long-term behavioral changes associated with specific HP programs, reliable and consistent estimates of attributable risk (incorporating considerations of cofactors), and appropriate use of technical tools, such as discounting.

Taking all of the workplace HP benefits and costs fully into account cannot be accomplished just by projecting and comparing the experiences of a hypothetical group of workers alternately exposed and not exposed to a health promotion effort. Rather, a full accounting requires comparison of the health and other experiences of two different groups of workers, projected over a period of several decades: the full complement of employees who would be working for the given firm absent the health promotion program, and the full complement who would be working for the employer given the health promotion program. From a purely financial "bottom line" point of view, employers are interested in the aggregate experience of their work force, not in the particular experience of individual employees (or groups) who participate in health promotion programs. Thus, the relevant question is not what the health and other 
costs would be for a continuing smoker versus one who quits; rather, one must compare, over decades, the stream of costs and benefits of smokers and their replacements as they die off, with the stream of quitters and their replacements (presumably fewer). Most writers on the economics of workplace health promotion have been quick to point to the costs of turnover, of replacing employees; but no one yet has discussed the fact that the employee who dies prematurely is likely to be replaced by a younger employee who, other things being equal, will have fewer health care needs and be further removed from retirement. To my knowledge, simulation of the costs and benefits of an entire work force with and without health promotion has never been attempted.

While the structure of this model is fairly easy to define, carrying out this kind of analysis obviously would be exceedingly difficult. Knowledge of the long-term effectiveness of most health promotion programs is relatively primitive, and the epidemiological data base for calculating attributable risk is not substantial. It has serious limitations with regard to the attributable risk of mortality, especially once one gets beyond a few well-described cases, such as hypertension control and smoking cessation, and useful data on attributable risks of mobidity verge on being nonexistent. Nevertheless, substantial improvements in the understanding of the economics of workplace health promotion can be achieved by moving from the simplistic model that has dominated thinking in the direction of the more substantial undertaking that is envisioned by this discussion. A few analysts have begun initial steps in this direction. $^{2}$

\section{Expected Findings}

Perhaps the clearest implication of our assessment of the conventional wisdom is that it is biased in favor of finding workplace HP programs good financial investments for firms. The logical question that follows is whether the bias is the principal factor producing the frequent findings of economic merit in workplace HP programs.

This question demands two answers. First, it cannot be concluded a priori whether a comprehensive analysis will reverse a positive finding from a simplistic analysis. At minimum. however. the former likely will diminish estimates of net cost savings.

Second, and perhaps of greater importance for the purposes of this article, conclusions about the economic merits of workplace HP programs are likely to vary substantially in both nature and degree, depending on such factors as the health problem addressed, type of program, type of employee population, and extent of management support. The generalization that the cost-saving potential of workplace health promotion likely falls short of that which has been suggested in the literature does not translate into any reasonable generalizations about the economic merits of workplace health promotion.

To illustrate how the considerations raised in this article may apply differentially to different program contexts, compare the implications of cigarette smoking and illicit drug use and their cessation. A workplace program directed at smoking cessation, if successful, will reduce certain health care costs, life insurance costs, disability, and absenteeism. It may increase productivity as well. However, one thing that it is almost certain to do, by virtue of its success, is to extend the lives of a subset of employees well into retirement, implying both pension and health care (and other) cost impli- 
cations (the latter when supplemental insurance is provided by the employer). Indeed, it is possible that the major health benefit will be realized during the retirement years.

In the instance of illicit drug abuse, by contrast, a successful prevention program may realize its major benefits in near-term improvements in productivity, simply because the use of disorienting drugs is so damaging to productivity. By comparison, longer-run health care and pension implications may be small. Thus, comparing the two situations, it is plausible that the drug abuse prevention program would produce a positive financial return, while the smoking cessation program might not, and that thorough analysis of such programs might yield results for the drug abuse program not too dissimilar to those that might be found in a simplistic analysis. In the case of smoking cessation, by contrast, the thorough analysis might reverse the simplistic analysis' finding of net profitability. At the same time, even given a net cost, the smoking cessation program may appear to be a highly cost-effective means of improving employees' health. In short, moving from the simplistic to the comprehensive analysis is not likely to alter conclusions in the same manner, nor to a similar degree, across types of HP program efforts.

In summary, the cost-saving potential and cost-effectiveness of workplace HP programs likely vary widely, depending on a number of programmatic, workplace, and analytical factors. The relatively uniformly positive appraisal that the literature has accorded the economics of workplace health promotion appears to be unjustified, if not necessarily wrong, and the base for a refined appreciation is limited. The road toward better understanding is paved with objective and more sophisticated analysis. As such analysis is produced, and as the corporate sector becomes a more sophisticated consumer of HP programming, questions of cost-effectiveness should increase in importance relative to questions of pure financial return.

\section{Interpretation and Use of Findings}

Four kinds of findings can emerge from an analysis of the economics of workplace health promotion. Each is of use to both the business and wellness communities, although to date only the first has achieved widespread attention. That object of attention is the conclusion that a program is effective in altering behavior and generates genuine net cost savings to the firm; that is, it is "profitable," a "bottom line" success. A second conclusion might be that a program is successful in altering behavior and does so in a manner that is cost-effective but not necessarily cost-saving. That is, the program does not generate net economic savings but it achieves a desirable behavior change in a manner that is relatively inexpensive; for reasons other than conventional profitability, the benefit, the nonmonetary effectiveness, is valued by the firm more than the net financial cost required to achieve it; the program is cost-effective. A third conclusion is that a program achieves some desired behavior change but at a cost that is excessive, from the firm's perspective. This kind of program is neither cost-saving nor cost-effective. Finally, a program can be relatively ineffective in changing behavior and improving the firm's financial situation.*

*A fifth possibility is that a program does not effect the desired health behavior change but produces economic benefits by increasing employee morale, thereby reducing absenteeism and turnover, increasing productivity, etc. 
One obvious implication of simply arraying the types of outcomes is that the concentration in the literature on the cost-saving potential of health promotion for business may be misguided. As noted early in this article, businesses' interests in health promotion are multiple, and emphasis on the economic bottom line addresses only one of these. Cost-effectiveness analysis provides a tool, and a perspective, that helps business decisionmakers to assess whether their noneconomic objectives can be attained at a reasonable price. Furthermore, the cost-saving criterion is a more restrictive one: many programs are likely to be cost-effective but not also clear moneymakers. Thus, if one focuses solely on the cost-saving potential of health promotion, ultimately one is likely to lead businesses toward evaluating health promotion more negatively than its supporters would like, and than the objective cost-effectiveness data might warrant.

A major value in economic analysis-perhaps the major value in a case pervaded by analytical and empirical uncertainty-is the ability of analysis to lend insight into the structure of problems, to assist decisionmakers to recognize the existence of questions and issues. The thorough analysis of workplace HP programs holds considerable potential to make a meaningful contribution as much in this context as in the generation of answers to the basic question of financial return. Consider, for example, the use of an analysis that finds future cost and benefit implications to be significant, while corporate decisionmakers tend to discount future implications heavily. There is a widespread perception that corporate decisionmakers take the short-term view of profitability, one that ignores everything that happens more than, say, five years into the future. In part. this may result from the executive's being rewarded on the basis of short-term performance indicators. In part. however, this may reflect a reasonable conclusion that the future is simply too hard to predict meaningfully. In the latter instance. by allowing decisionmakers to vary the discount rate in the analytical model, analysts can permit decisionmakers to assess whether the later implications of a health promotion program warrant serious consideration.

A second example relates to the meaning of cost containment in a business context. Given the preeminence of health care costs in driving economic interest in health promotion, it is easy to understand how corporate decisionmakers, particularly those in medical benefits departments, would interpret the containment of health care costs as contributing to containment of overall business costs, and hence to increased profitability. Thus, a medical benefits manager (for example) who has been convinced that a health promotion program will decrease health care costs, might confidently recommend to the corporation its adoption as a cost containment device. A thorough analysis of all of the economic ramifications of the health promotion program might alert the manager, and the corporation, to the pension implications of the program. Given the relative isolation of units within a large corporation, it is entirely plausible that the non-health care cost implications of a health promotion program might never be considered absent a thorough and perhaps external analysis of the economics of the program. $^{5}$

\section{CONCLUSION}

The contemporary interest in health promotion is a relatively recent phenomenon, one that has been molded in important ways by the clash between medical progress 
and the era of health care limits. Health promotion has arisen as a quiet counterpoint to the increasing sophistication and expense of "hi-tech" medicine. While the public's attention remains riveted on the drama of replacing that most quintessential human organ, the heart, with a mechanical device, a growing body of medical and public health professionals is urging that same public to look inward for true progress in combatting morbidity and premature mortality. At its most fundamental, the message of the new health promotion is to heed the lessons of a bygone era when people did not have the option of relinquishing control of their own health and entrusting it to the medical establishment. The message of health promotion is that medical care is not a substitute for self-care. Rather, it is a supplement to self-care, a complement, that collectively we as a society erroneously chose to elevate to the status of alternative.

A creature of the times, health promotion has come to be defined in economic terms. In an era of cost containment, health promotion is the latterday version of the public health folk wisdom that an ounce of prevention is worth a pound of cure. It is a reflection of the power of the cost containment mentality that few of us can contemplate that venerable adage, or health promotion, without inferring an economic interpretation.

In emphasizing the economic attractions of health promotion, most of the wellness community has worked from a motivation that is well-intentioned and has employed a logic that is readily comprehensible, if flawed. The novelty of health promotion, in its present context, accounts in large part for the limited amount of sophisticated analysis addressing its economic merits. Yet as the health promotion movement grows and matures, such analysis is forthcoming. Prominent economists are beginning to turn their attention to HP issues, and their message is viewed by many within the wellness community as not entirely salutary and indeed even threatening. Louise Russell has written a new book in which disease prevention is labelled as being neither riskless nor costless, and not inherently economically preferable to medical treatment. ${ }^{2}{ }^{2}$ Thomas Schelling has evaluated the economics of smoking prevention and found the profitability argument wanting. ${ }^{23}$ Other scholars, cited earlier, have contributed analyses that reinforce the message that health promotion has real economic costs as well as benefits. ${ }^{15,16,19}$ Yet all of these authors also emphasize that health promotion has real health benefits, as well as economic ones.

The response to this message by the sellers of health promotion will be well worth watching. The predominant interest of much of the wellness community has always been the health benefit to be derived from HP. For these individuals, the purported financial profitability of HP programming has been at minimum a convenient vehicle for selling HP, at maximum an essential one. What will happen in the cases in which the tires on this vehicle are deflated? Will the sellers of business HP programming be successful in marketing their programs by relying on the true merits, the health and welfare implications of HP programs and possibly their cost-effectiveness (as opposed to their cost savings)? The chilling quality of this question points to pragmatic concerns about placing all of one's marketing eggs in the basket of profitability, and it raises serious questions about the ethics of relying primarily on an economic argument for initiatives that have health and well-being as their raison d'etre.

Looking to the future, the trend in economic analysis of HP programs seems clear: analysis will increase in sophistication and the resultant findings will be less uniformly positive about the financial profitability of health promotion than have been the findings published to date. In their greater sophistication, the emerging analyses should 
broaden the perspectives of business consumers and wellness sellers of HP programs. The issue of the cost-effectiveness of health promotion should rise on both the public and private sector agendas, while the orientation toward cost savings recedes accordingly. This is not to suggest that the latter will disappear as a basis for decisionmaking-for some businesses it may remain the sine qua non-rather, that it will take its proper place next to the several other criteria that warrant attention in health, and business, decisionmaking.

Ultimately, this is a positive message. If many health promotion efforts have great potential to be cost-effective means of improving employees' health, of bettering the quality of work life, then sound economic analyses of workplace HP programs will convey this message to both employers and health professionals interested in health promotion. In an almost perverse fashion, the relatively negative findings about pure financial profitability may force both buyer and seller to rediscover the principal virtue of $\mathrm{HP}$ programs, one that in the rush to save a buck we often tend to forget: HP programs are fundamentally health efforts, not cost containment devices.

A corollary of this assessment is that both employers and health professionals will have to refine their appreciation of economic analysis. As they do, and as substantive knowledge emerges, the courtship of wellness and the workplace will find itself on sturdier ground.

My appreciation of the issues discussed in this article has benefitted from discussions with Thomas Wickizer, Richard Wolfe, and Joan Schildroth. Patricia Warner made helpful suggestions on an earlier draft, as did an anonymous reviewer.

\section{References}

1. Fielding JE, Breslow L: Health promotion programs sponsored by California employers. $A m$ J Public Health 73:538-542, 1983.

2. Leviton LC, et al.: Worksite Health Promotion and Its Status in Southwestern Pennsylvania. Health Policy Institute Policy Series \#10. Pittsburgh, PA: Graduate School of Public Health, University of Pittsburgh, July 1985.

3. Terborg JR: Health promotion at the worksite: A research challenge for personnel and human resources management, in KH Rowland and GR Ferris (eds) Research in Personnel and Human Resources Management, Greenwich, CT, JAI Press, 4:225-267, 1986.

4. Davis MF, Rosenberg K, Iverson DC. Vernon TM, Bauer J: Worksite health promotion in Colorado. Public Health Rep 99:538-543, 1984.

5. Clement J, Gibbs DA: Employer consideration of health promotion programs: financial variables. J. Public Health Pol 4:45-55, 1983

6. Arnett RH, Cowell CS, Davidoff LM, Freeland MS: Health spending trends in the 1980s: Adjusting to financial incentives. Health Care Fin Rev 6(3):1-26, 1985.

7. Shepard DS, Pearman LA: Incentives for health promotion at the workplace: A review of programs and their results. Boston, MA, Center for the Analysis of Health Practices, Harvard School of Public Health, October 1982.

8. Warner KE, Murt HA: Economic incentives for health. Ann Rev Pub Health 5: 107-133, 1984.

9. Hartman SW, Cozzetto J: Wellness in the workplace. Personnel Administrator, pp. 108-1 17, August 1984.

10. Brennan AJJ: Health promotion: What's in it for business and industry? Health Educ $Q$ 9(supplement):9-19, 1982.

11. Schwartz RM, Rollins PL: Cost benefit of wellness strategies. Bus and Health 2(10):24-26, 1985.

12. Kristein MM: How much can business expect to profit from smoking cessation? Preventive Med 12:358-381, 1983.

13. Kristein MM: The economics of health promotion at the worksite. Health Educ $Q 9$ (supplement):27-36, 1982 . 
14. Fielding JE: Preventive medicine and the bottom line. J Occup Med 21:79-88, 1979.

15. Gori GB, Richter BJ, Yu WK: Economics and extended longevity: A case study. Preventive Med 13:396-410, 1984.

16. Gori GB, Richter BJ: Macroeconomics of disease prevention in the United States. Science 200:1124-1130, 1978.

17. Otfice of Technology Assessment, U.S. Congress: Smoking-related deaths and financial costs. Staff Memorandum. Washington, DC: OTA, September 1985.

18. Fries JF: Aging, natural death, and the compression of morbjdity. $N$ Engl J Med 303:130$135,1980$.

19. Leu RE, Schaub T: Does smoking increase medical care expenditure? Soc Sci Med 17:1907$1914,1983$.

20. U.S. Department of Health, Education, and Welfare, Public Health Service: Smoking and Health: A Report of the Surgeon General. Washington, DC: Government Printing Office, 1979.

21. Warner KE, Luce BR: Cost-Benefit and Cost-Effectiveness Analysis in Health Care: Principles, Practice, and Potential. Ann Arbor, MI: Health Administration Press, 1982.

22. Russell LB: Is Prevention Better than Cure? Washington, DC: Brookings Institution, 1986.

23. Schelling TC: Economics and cigarcttes. Preventive Med 15:549-560, 1986. 